\title{
Managed Health Care and Utilization of Fecal Occult Blood Testing for Colorectal Cancer Screening: a National Database Study
}

\begin{abstract}
Daniel Bushyhead, $M D^{7}$ and Paul Fishman, $P h D^{2}$
'Division of Gastroenterology, Department of Medicine, University of Washington School of Medicine, Seattle, WA, USA; '2School of Public Health, University of Washington, Seattle, WA, USA.
\end{abstract}

Abbreviations

HMO

USPSTF
Health maintenance organization

United States Preventive Services Task Force

J Gen Intern Med 35(1):357-9

DOI: $10.1007 / \mathrm{s} 11606-019-05504-7$

(c) Society of General Internal Medicine 2019

\section{INTRODUCTION}

The United States Preventive Services Task Force (USPSTF) recommends colorectal cancer screening in adults aged 50 to 75 using either fecal occult blood testing (including fecal immunochemical test) or lower endoscopy. ${ }^{1}$ However, in 2015 , less than two-thirds of eligible adults were compliant with these screening recommendations. ${ }^{2}$

The influence of health insurance on colorectal cancer screening uptake is unknown. Although certain managed care consortiums such as Kaiser Permanente have successfully implemented programmatic screening using fecal occult blood testing, ${ }^{3}$ the influence of managed care as an overall category of health insurance has not been examined in relation to colorectal cancer screening. The purpose of this study was to determine if state-level managed care market penetration was associated with increased prevalence of fecal occult blood testing (FOBT).

\section{METHODS}

This was a retrospective, national database study. Crude prevalence survey data from the biennial Centers for Disease Control and Prevention's Behavioral Risk Factor Surveillance System were utilized to obtain state-level trends in the utilization of either FOBT or colonoscopy. State-level health maintenance organization (HMO) market penetration was obtained from the Kaiser Family Foundation. All data were obtained for 2016. Linear regression analysis was used to determine the association between any two particular variables.

Published online October 28, 2019

\section{RESULTS}

During 2016, 67.8\% of subjects surveyed nationally reported compliance with USPSTF recommendations for colorectal cancer screening. Overall, $8.7 \%$ of subjects reported receipt of FOBT in the past year, and $63.6 \%$ reported receipt of a colonoscopy within the past 10 years.

The national mean HMO market penetration was $24.5 \%$ (standard deviation $=13.6 \%)$, and state-level prevalence was variable (range 0.2-59.2\%) (Table 1). HMO market penetration was positively correlated with utilization of FOBT at the state level $\left(R^{2}=0.36, p<0.001\right.$; see Fig. 1$)$. There was no correlation between HMO market penetration and overall compliance with USPSTF recommendations for colorectal cancer screening $\left(R^{2}=0.0286, p=0.12\right)$, or between HMO market penetration and receipt of colonoscopy within the past 10 years $\left(R^{2}=0.0082, p=0.27\right)$.

\section{DISCUSSION}

Our analysis of national survey data indicates that despite relatively low utilization of FOBT, receipt of this low-cost screening test was more common in states with higher HMO market penetration. National variation in managed care has previously been associated with increased uptake of breast and cervical cancer screening. ${ }^{4}$ While the influence of HMO prevalence on colorectal cancer screening has been studied at the county-level, ${ }^{5}$ this is the first analysis of state-level data.

The etiology of our findings is unclear. Although one might expect that an increase in FOBT use would be associated with an overall increase in the proportion of screened patients, we found no such correlation. It is thus possible that HMOs are associated with increased enthusiasm for FOBT in lieu of colonoscopy. If this finding is corroborated in other studies, the mechanism for this effect should be explored to determine if this is related to patient or HMO preference, incentives from payers related to cost of care (FOBT is associated with lower clinical costs than colonoscopy ${ }^{6}$ ), or other factors.

The lack of subject-specific clinical information is the largest limitation of this study given our reliance on survey data. The surveys were also based on patient recollection of screening and modality, rather than objective clinical data. Data 
Table 1 State-Level Prevalence of Colonoscopy, Fecal Occult Blood Test, and HMOs in 2016

\begin{tabular}{|c|c|c|c|}
\hline State & HMO market penetration (\%) & Colonoscopy in past 10 years $(\%)$ & Fecal occult blood test in past year $(\%)$ \\
\hline Alabama & 7.2 & 33.9 & 8.9 \\
\hline Alaska & 0.2 & 62.2 & 7.3 \\
\hline Arizona & 32.6 & 59.3 & 10.8 \\
\hline Arkansas & 14.2 & 61.3 & 9.9 \\
\hline California & 59.2 & 60.9 & 23.8 \\
\hline Colorado & 16.6 & 62.9 & 9.2 \\
\hline Connecticut & 7 & 73.4 & 8.9 \\
\hline Delaware & 26.9 & 69.6 & 5.2 \\
\hline Florida & 35.6 & 62.2 & 15.2 \\
\hline Georgia & 27 & 58.3 & 12.8 \\
\hline Hawaii & 58.2 & 63.9 & 19.9 \\
\hline Idaho & 9.2 & 60 & 4.9 \\
\hline Illinois & 24 & 61.5 & 5.2 \\
\hline Indiana & 23.4 & 61 & 7.8 \\
\hline Iowa & 9.3 & 66.1 & 5.8 \\
\hline Kansas & 19.3 & 64.3 & 6.7 \\
\hline Kentucky & 36.4 & 66 & 10.4 \\
\hline Louisiana & 35.3 & 60.6 & 8.3 \\
\hline Maine & 11.5 & 73.3 & 6.7 \\
\hline Maryland & 34.2 & 66.6 & 9.2 \\
\hline Massachusetts & 34.2 & 73.1 & 8.6 \\
\hline Michigan & 38.9 & 67.2 & 8.7 \\
\hline Minnesota & 26.1 & 70.3 & 6.1 \\
\hline Mississippi & 25.7 & 57.7 & 8.8 \\
\hline Missouri & 15.8 & 62.8 & 6.2 \\
\hline Montana & 4.4 & 57.9 & 8 \\
\hline Nebraska & 15.1 & 63.3 & 6.9 \\
\hline Nevada & 37 & 58.1 & 10.2 \\
\hline New Hampshire & 21.3 & 72.7 & 6.6 \\
\hline New Jersey & 25 & 62.9 & 7.4 \\
\hline New Mexico & 45.2 & 55.2 & 7.3 \\
\hline New York & 35.6 & 66.2 & 7.4 \\
\hline North Carolina & 7.6 & 69.6 & 9.2 \\
\hline North Dakota & 18.5 & 62.2 & 5.8 \\
\hline Ohio & 31.7 & 63.6 & 8.1 \\
\hline Oklahoma & 7.1 & 55 & 9.2 \\
\hline Oregon & 40.2 & 63.4 & 13.2 \\
\hline Pennsylvania & 31.3 & 65.3 & 7.4 \\
\hline Rhode Island & 32.6 & 71.5 & 7.8 \\
\hline South Carolina & 24.3 & 66.8 & 7.6 \\
\hline South Dakota & 12 & 63.5 & 7.3 \\
\hline Tennessee & 32.3 & 62.8 & 9.6 \\
\hline Texas & 24.7 & 56.1 & 8.7 \\
\hline Utah & 30.3 & 70.5 & 2.8 \\
\hline Vermont & 2.8 & 70.1 & 5.5 \\
\hline Virginia & 20.4 & 67.6 & 7.8 \\
\hline Washington & 31.5 & 64.2 & 12 \\
\hline West Virginia & 29.8 & 63.3 & 10 \\
\hline Wisconsin & 34.4 & 70.2 & 7.1 \\
\hline Wyoming & 0.8 & 59.4 & 4.5 \\
\hline
\end{tabular}

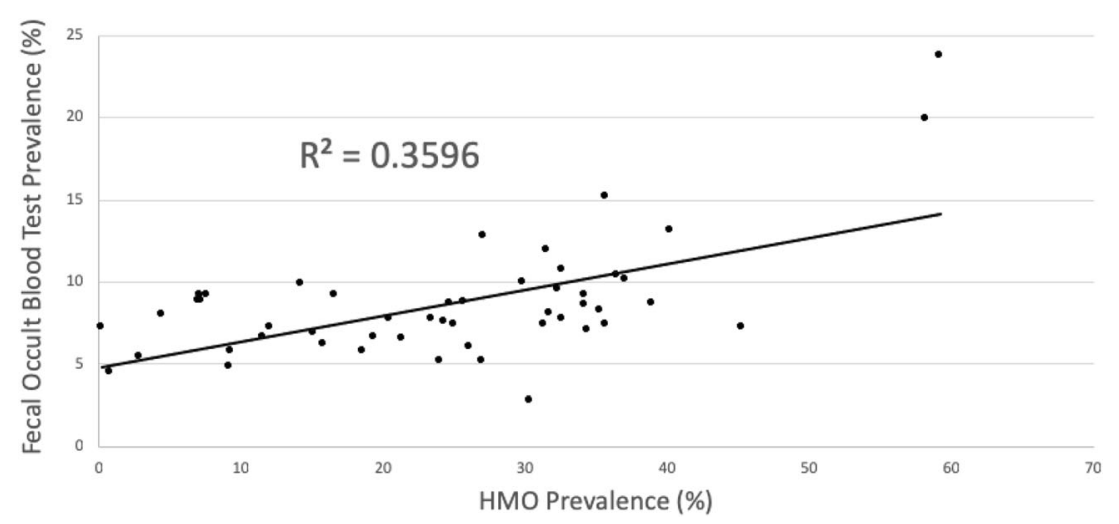

Fig 1. State-level HMO Insurance Status and Prevalence of Fecal Occult Blood Testing 
regarding the results of FOBT, and whether positive results accounted for a portion of the recorded colonoscopies, were not available. Additionally, as an observational study, there is also the potential for selection bias. However, the use of a large, well-studied survey database is a strength in allowing us to examine national trends.

In conclusion, HMO market penetration at the state level was associated with increased utilization of FOBT for colorectal screening, with no difference in overall compliance with colorectal cancer screening. Our findings should lead to further research on mechanisms accounting for increase utilization of FOBT by HMOs, and relative efficacy and cost-effectiveness of FOBT by HMOs in comparison to other health insurers.

Corresponding Author: Daniel Bushyhead, MD; Division of Gastroenterology, Department of Medicine University of Washington School of Medicine, 1959 NE Pacific St, Seattle, WA 98195, USA (e-mail: dwb85@uw.edu).

\section{Compliance with Ethical Standards:}

Conflict of Interest: The authors declare that they do not have a conflict of interest.

\section{REFERENCES}

1. US Preventive Services Task Force, Bibbins-Domingo K, Grossman DC, Curry SJ, et al. Screening for Colorectal Cancer: US Preventive Services Task Force Recommendation Statement. JAMA 2016;315:2564-2575.

2. White A., Thompson T.D., White M.C., et al: Cancer screening test use-United States, 2015. MMWR Morb Mortal Wkly Rep 2017; 66: pp. 201-206.

3. Jensen CD, Corley DA, Quinn VP, et al. Fecal immunochemical test program over 4 rounds of annual screening: a retrospective study. Ann Intern Med 2016;164:456-63.

4. Baker LC, Phillips KA, Haas JS, Liang SY, Sonneborn D. The effect of area HMO market share on cancer screening. Health Serv Res 2004;39:175172.

5. Shariff-Marco S, Breen N, Stinchcomb DG, Klabunde CN. Multilevel predictors of colorectal cancer screening use in California. Am J Manag Care 2013;19(3):205-216.

6. Subramanian S, Tangka FKL, Hoover S, et al. Costs of colorectal cancer screening provision in CDC's Colorectal Cancer Control Program: Comparisons of colonoscopy and FOBT/FIT based screening. Eval Program Plann 2017;62:73-80.

Publisher's Note Springer Nature remains neutral with regard to jurisdictional claims in published maps and institutional affiliations. 